\title{
Trends and social patterning of birthweight in Sheffield, 1985-94
}

\author{
N J Spencer, S Logan, L Gill
}

\begin{abstract}
Aim-To describe the trends in birthweight and their association with socioeconomic status in a 10 year birth cohort in Sheffield.

Methods-Data for all live singleton births were extracted from the Sheffield Child Development Study (SCDS) database for 1985-94. Enumeration districts (EDs), derived from postcodes, were ranked into deciles by Townsend Deprivation Index (TDI), based on the 1991 census. Birthweight by 500 g group and mean birthweights for the city and by ED decile were calculated by year. $\chi 2$ analyses for linear trend were calculated. The proportion of variance in birthweight explained by ED decile and raw TDI score was estimated by year. Absolute risk difference of birthweight $<3500 \mathrm{~g}$ for the most compared with the least deprived deciles and proportion of births $<3500 \mathrm{~g}$ statistically "attributable" to social inequality were calculated. Results-The mean birthweight for all births increased by $34 \mathrm{~g}$ between 1985 and 1994. This difference is largely accounted for by a positive trend in births $\geqslant 3500 \mathrm{~g}$ and a negative trend in births of 3000-3499 g. Similar trends were noted across all ED deciles. Around $10 \%$ of the variance in birthweight was explained by area deprivation level. Absolute risk difference for births $<3500 \mathrm{~g}$ was $12.5 \%$ for the 10 years (range 8.3-18.4). The proportion of births $<3500 \mathrm{~g}$ statistically "attributable" to social inequality for the 10 year period was $9.6 \%$ (range $4.3-15.5$ ). Conclusions-Despite an overall increase in mean birthweight, large social differences persisted during the study period. An average of 350 births a year were not in the group ( $\geqslant 3500 \mathrm{~g}$ ) bestowing most health advantage throughout the life course, as a result of social inequality.
\end{abstract}

(Arch Dis Child Fetal Neonatal Ed 1999;81:F138-F140)

Keywords: birthweight; socioeconomic status

Systematic Reviews Training Unit

Department of

Epidemiology and

Biostatistics

Institute of Child

Health

London

S Logan

Correspondence to: Professor NJ Spencer School of Postgraduate Medical Education University of Warwick Coventry CV4 7AL.

Accepted 26 April 1999
Methods

Birthweight and postcode of the mother's address at birth were extracted from the Sheffield Child Development Study (SCDS) for all singleton births for the 10 years 1985-94. Birthweight data were reported by midwives on an SCDS proforma for each child at, or soon after, birth. Postcodes were converted to enumeration districts (EDs) using MIDAS software ${ }^{5}$ and ranked into deciles by Townsend Deprivation Index 6 (TDI), based on the 1991 census. Mean birthweight and birthweight distribution across $500 \mathrm{~g}$ groups for the whole city and for each ED decile by year were computed. $\chi^{2}$ analysis for linear trend over the study period by each $500 \mathrm{~g}$ group was calculated for the whole city and for each ED decile. Correlations between birthweight and ED deciles and raw TDI score as a continuous variable were calculated for each year, to give an estimate of the proportion of variance in birthweight explained by ED decile and raw TDI score.

The absolute risk difference of birthweight $<3500 \mathrm{~g}$ for the most $v$ s the least deprived deciles by year was calculated. The proportion of births $<3500 \mathrm{~g}$ statistically "attributable" to social inequality by year and by 5 year period (1985-89; 1990-94) was calculated by subtracting the number of births $<3500 \mathrm{~g}$ obtained when the observed rate in ED decile 1 was applied to the whole population from the observed number of births $<3500 \mathrm{~g}$, and expressing the resulting reduction as a percentage.

\section{Results}

There were 58552 live singleton births in Sheffield between 1985 and 1994. Birthweight data were missing for five births and postcode data were unavailable for a further 257 births. The live births $(n=58547)$ were included in the analysis of birthweight trends for the whole city and 58290 live births were included in the analysis of trends by deprivation index.

Mean birthweight of singleton births in Sheffield increased by $34 \mathrm{~g}$ between 1985 and 1994. A significant positive linear trend was noted for births $\geqslant 3500 \mathrm{~g}$ and a negative linear trend for births between 3000-3499 g (table 1). Births $<1500 \mathrm{~g}$ showed a positive linear trend over time which just reached conventional levels of significance, but births $<2500 \mathrm{~g}$ did not show an overall increase (table 1).

Ten year trends in birthweight distribution for each ED decile were similar to those for the whole city. There was no evidence of differential trends in privileged and deprived deciles. Birthweight was negatively correlated with increasing levels of material deprivation in all 10 years studied. Over the 10 years studied, 
Table 1 Trends by birthweight group for the whole city (58 552 live singleton births) 1985-94

\begin{tabular}{|c|c|c|c|c|c|c|c|}
\hline Year & $\begin{array}{l}\text { Mean } \\
\text { birthweight } \\
(S E)\end{array}$ & $\begin{array}{l}<1500 g \\
\%(\mathrm{No})\end{array}$ & $\begin{array}{l}1500-999 \mathrm{~g} \\
\%(\mathrm{No})\end{array}$ & $\begin{array}{l}2000-499 \mathrm{~g} \\
\%(\mathrm{No})\end{array}$ & $\begin{array}{l}2500-999 g \\
\%(\mathrm{No})\end{array}$ & $\begin{array}{l}3000-499 \mathrm{~g} \\
\%(\mathrm{No})\end{array}$ & $\begin{array}{l}\geqslant 3500 \mathrm{~g} \\
\%(\mathrm{No})\end{array}$ \\
\hline $1985(\mathrm{n}=5866)$ & 3287 & $1.04(61)$ & $1.53(90)$ & $4.84(284)$ & $17.64(1035)$ & $38.61(2265)$ & $36.32(2131)$ \\
\hline $1986(\mathrm{n}=6137)$ & 3286 & $1.08(66)$ & $1.53(94)$ & $4.90(300)$ & $18.01(1105)$ & $38.16(2342)$ & $36.34(2230)$ \\
\hline $1987(\mathrm{n}=6127)$ & 3306 & $0.88(54)$ & $1.47(90)$ & $4.59(281)$ & 16.86 & $38.40(2353)$ & $37.80(2316)$ \\
\hline $1988(n=5679)$ & 3326 & $1.09(62)$ & $1.29(73)$ & $4.40(250)$ & $16.66(946)$ & $37.35(2121)$ & $39.21(2227)$ \\
\hline $1989(\mathrm{n}=5469)$ & 3292 & $1.19(65)$ & $1.23(67)$ & $4.64(254)$ & $17.86(977)$ & 38.27 (2093) & $36.81(2013)$ \\
\hline $1985-9$ & 3299 & $1.05(308)$ & $1.41(414)$ & $4.67(1369)$ & $17.40(5096)$ & $38.17(11174)$ & 37.29 (10917) \\
\hline $1990(\mathrm{n}=5513)$ & 3296 & $1.09(60)$ & $1.31(72)$ & $4.84(267)$ & $17.88(986)$ & $37.75(2081)$ & $37.13(2047)$ \\
\hline $1991(n=5683)$ & 3304 & $0.84(48)$ & $1.44(82)$ & $4.82(274)$ & 18.18 & $36.97(2101)$ & $37.74(2145)$ \\
\hline $1992(\mathrm{n}=5969)$ & 3311 & $0.95(57)$ & $1.68(100)$ & $5.28(315)$ & $16.97(1013)$ & $36.27(2165)$ & 38.85 (2319) \\
\hline $1993(\mathrm{n}=6134)$ & 3336 & $1.17(72)$ & $1.37(84)$ & $4.84(297)$ & $16.92(1038)$ & $34.48(2115)$ & $41.21(2528)$ \\
\hline $1994(n=5970)$ & 3321 & $1.54(92)$ & $1.32(79)$ & $4.71(281)$ & $16.35(976)$ & $36.43(2175)$ & $39.65(2367)$ \\
\hline $1990-4$ & 3315 & $1.12(329)$ & $1.42(417)$ & $4.90(1434)$ & $17.24(5046)$ & $36.34(10637)$ & $38.97(11406)$ \\
\hline$\chi^{2}$ for linear trend & & 3.88 & 0.29 & 0.67 & 2.92 & 26.18 & 33.38 \\
\hline $\mathrm{p}$ Value & & $<0.05$ & $>0.50(\mathrm{NS})$ & $>0.10$ (NS) & $>0.10(\mathrm{NS})$ & $<0.0001$ & $<0.0001$ \\
\hline
\end{tabular}

Table 2 Proportion of births $<3500 \mathrm{~g}$ statistically "attributable" to social inequality by year

\begin{tabular}{lllll}
\hline & $\begin{array}{l}\text { Observed } \\
\text { births } \\
<3500 \mathrm{~g} \\
\text { (O) }\end{array}$ & $\begin{array}{l}\text { Expected } \\
\text { births } \\
<3500 \mathrm{~g} \\
\text { (E) }\end{array}$ & $\begin{array}{l}\text { Observed } \\
\text { minus } \\
\text { Expected } \\
\text { (O-E) }\end{array}$ & $\begin{array}{l}\text { Proportion } \\
\text { "attributable" } \\
\text { to social } \\
\text { inequality } \\
(\%) \\
(O-E / O)\end{array}$ \\
\hline 1985 & 3735 & 3408 & 327 & $8.8 \%$ \\
1986 & 3907 & 3498 & 409 & $10.5 \%$ \\
1987 & 3811 & 3498 & 423 & $11.1 \%$ \\
1988 & 3452 & 3163 & 289 & $8.4 \%$ \\
1989 & 3456 & 3167 & 289 & $8.4 \%$ \\
$1985-89$ & 18361 & 16601 & 1760 & $9.6 \%$ \\
1990 & 3466 & 2927 & 539 & $15.5 \%$ \\
1991 & 3538 & 3376 & 162 & $4.6 \%$ \\
1992 & 3650 & 3271 & 379 & $10.4 \%$ \\
1993 & 3606 & 3330 & 276 & $7.7 \%$ \\
1994 & 3603 & 3272 & 331 & $9.2 \%$ \\
$1990-94$ & 17863 & 16156 & 1707 & $9.6 \%$ \\
\hline
\end{tabular}

*Derived by applying observed rate in ED decile 1 to whole population

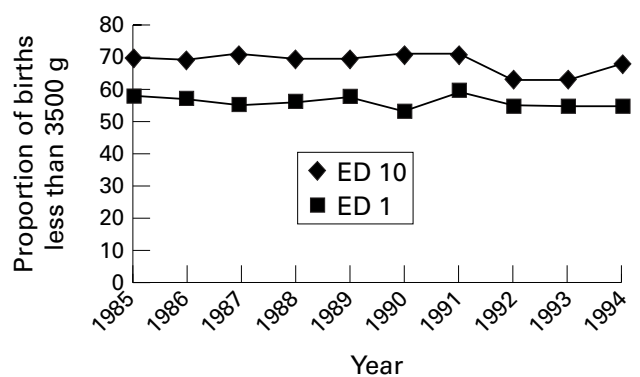

Figure 1 Absolute risk of birth less than $3500 \mathrm{~g}$ by ED deciles 1-10 between 1985 and 1994.

$8.6-13.3 \%$ of the variance in mean birthweight is explained by ED decile of residence and $8.8-13.1 \%$ by raw TDI score of ED decile of residence.

The absolute risk difference of birthweight $<3500 \mathrm{~g}$ between the most and the least deprived ED deciles was $12.5 \%$ for the 10 years, with a range of 8.3 (in 1992) and 18.4 (in 1990) (fig 1). No consistent change over time was noted in risk difference. The proportion of births $<3500$ g statistically "attributable" to social inequality was $9.6 \%$ for the whole 10 year period, with a range of $4.6 \%$ (in 1991) and $15.5 \%$ (in 1990) (table 2).

\section{Discussion}

Mean birthweight in Sheffield between 1985 and 1994 showed an increase consistent with previously reported national trends, ${ }^{3}$ with a positive linear trend in births $\geqslant 3500 \mathrm{~g}$ and a negative linear trend in births between 3000$3499 \mathrm{~g}$.

A social gradient in low birthweight has been shown using occupational ${ }^{4}$ and area based SES measures. ${ }^{7}$ The social gradient in mean birthweight and the proportion of babies in heavier birthweight groups has been less well documented. The negative social gradients (from least to most deprived) in mean birthweight in Sheffield are similar to those reported from Gothenburg, Sweden, ${ }^{8}$ although the population mean for Sheffield is about 200 g lower. The finding that the deprivation level of area of residence accounts for $10 \%$ of the variance in birthweight confirms the importance of socioeconomic factors in birthweight determination.

Perinatal and infant mortality is lowest in births $\geqslant 3500 \mathrm{~g}$, ${ }^{9}$ and standardised mortality ratios for adult cardiovascular disease have been estimated as 119 for birthweights of $<2500 \mathrm{~g}$ and 74 for birthweights $>3900 \mathrm{~g} .{ }^{10} \mathrm{In}$ this study the absolute risk difference (most vs least deprived) for a birthweight of $<3500 \mathrm{~g}$ was $12.5 \%$ for the 10 years studied; $9.6 \%$ of births at $<3500 \mathrm{~g}$ are significantly "attributable" to social inequality. These infants are prevented by their social circumstances from being in the birthweight group associated with the most advantageous survival chances.

This study did not show differential trends over the 10 years studied in mean birthweight in privileged and deprived deciles. An increase in social difference in mean birthweight has been reported over a two year period (198991) in the Czech Republic, associated with a fall in mean birthweight for all singleton births of 31 g. ${ }^{11}$ Comparison with Sweden during the same period showed no decline in mean birthweight in Sweden and no increase in differential between privilege and deprivation in Sweden. The increase in inequalities in the UK since 1979, which has been associated with a widening of the mortality gap, particularly affecting young adults, ${ }^{12}$ might have been expected to be reflected in an increase in the social differential in birthweight in Sheffield - a city severely affected by industrial decline in the early 1980s. The effect noted over two years in the Czech Republic may reflect a more rapid decline in living standards affecting a larger proportion of the population. 
The mechanism by which socioeconomic status exerts an effect on birthweight remains unclear but must operate through a range of intervening variables. A recent study using path analysis shows that stress in pregnancy has no direct effect on birthweight, but exerts its effect through smoking and alcohol consumption. ${ }^{13}$ Stress may be one of the mechanisms by which socioeconomic status exerts its effect.

Differences observed in birthweight in this study have profound implications for perinatal, infant, and adult health. They reinforce the importance of social inequalities in health determination throughout the life course and add strength to the contention that "further improvements in birth weight depend, in particular, on the weights of babies from lower social class backgrounds increasing to resemble those in higher classes."13

We thank Professor David Hall for permission to use the Sheffield Child Development Study data and Sue Scholey for extracting the relevant data. 1 Barker DJP, ed. Fetal and infant origin of adult disease.
London: BMJ Publishing Group, 1992.

2 Alberman E. Are our babies becoming bigger? f Roy Soc Med 1991;84:257-60.

Med 1991;84:257-60.
3 Power C. National trends in birth weight: implications for future adult disease. BMF 1994;308:1270-1.

4 Drever F, Whitehead M. Health inequalities. ONS, Series DS No.15. London: The Stationery Office, 1997.

5 Manchester Information Datasets and Associated Services. $M I D A S P C / E D$ conversion directory. Manchester: University of Manchester, 1995.

6 Townsend P, Philimore P, Beattie A. Health and deprivation: inequality and the North. London: Croom Helm, 1988.

7 Reading RF, Openshaw S, Jarvis SN. Measuring child health inequalities using aggregations of Enumeration Districts. $\mathcal{F}$ Public Health Med 1990;12:160-7

8 Elmen H, Hoglund D, Karlberg P, Niklasson A, Nilsson W. Birth weight for gestational age as a health indicator: birth weight and mortality measures at a local area level. Eur $\mathcal{F}$ Public Health 1996;6:137-41.

9 Plablic HJ, Pharaoh POD. Child health statistical review, 1996. Arch Dis Child 1996;75:527-33.

10 Barker DJP, Osmond C, Simmonds SJ, Wield GA. The relation of small head circumference and thinness at birth to death from cardiovascular disease in adult life. BMF 1993;306:422-6.

11 Koupilova I, Vagero D, Leon DA, Pikhart H, Prikavsky V, Holcik J, Bobak M. Social variation in size at birth and preterm delivery in the Czech Republic and Sweden, 1989-91. Paediatr Perinat Epidemiol 1998;12:7-24.

12 McLoone P, Boddy FA. Deprivation and mortality in Scotland, 1981 and 1991. BMF 1994;308:1125-8.

13 Sheehan TJ. Stress and low birth weight: a structural modelling approach using real life stressors. Social Sci Med 1998;47:1503-12. 